\title{
The Official Promotion Incentive: A New Re-Estimation and Re-Examination
}

\author{
Chen Feng \\ University of New South Wales, Sydney, Australia \\ Meng Qiu \\ Xi'an Jiaotong University, Xi'an, China \\ Rong Kang, Dong Wang, Bei-bei Shi \\ Northwest University, Xi’an, China
}

\begin{abstract}
Based on three major theories, the Chinese local officials' promotion incentive could be influenced by economic performances, political relationships, and financial performances. However, there were some researchers focusing on these promotion mechanisms and then they got different outcomes. This paper achieves the goal for exploring the influence factors of officials' promotion by using OLS empirical test. From collecting the data of Chinese local officials and cities' economic conditions, we find that economic performances and political relationships can have a significant effect on officials' promotion, but financial performances cannot have this effect. And the experiences and lesson of this research have some reference for exploration of Chinese local officials’ promotion incentive.
\end{abstract}

Keywords: officials’ promotion incentive, economic performance, political relationships, financial performances

\section{Introduction}

Since the Chinese reform and opening up, officials' selection and promotion has been changed from focusing on political relationships to economic performances. There are plenty of theories explaining the officials' promotion incentive, which can be classified as follows: (1) Economic performances factor can have a significant effect on promotion (Zhou, 2007; Wang \& Xu, 2008; Yang, Wang, \& Nie, 2013; Yang \& Zheng, 2013; Qiao, Zhou, \& Liu, 2014; Luo, She, \& Chen, 2015), which focuses on probability of local officials' promotion influenced by their domination areas' economic development; (2) Economic performances factor cannot influence the local officials' promotion incentive (Landry, 2003; Tao, Su, Lu, \& Zhu, 2010; Yao \& Zhang, 2013), these researchers thought that economic development cannot be reflected on promotion aspect, and different local officials may have different reactions when they faced promotion mechanism; (3) Political relationships factor can have a significant effect on promotion (Yang \& Zheng, 2013); and (4) Financial performances can influence promotion (Guo, 2007). Because of different theories explaining this problem, we will observe economic performances, political relationships, and financial performances, respectively, and find out whether they can impact on local officials’ promotion significantly or not.

Chen Feng, Master, Australia Business School, University of New South Wales. Email: fc452062658@163.com.

Meng Qiu, Ph.D., School of Management, Xi'an Jiaotong University.

Rong Kang, Associate Professor, School of Economics and Management, Northwest University.

Dong Wang, Mrs, School of Economics and Management, Northwest University.

Bei-bei Shi, Ph.D., School of Economics and Management, Northwest University. 


\section{Data Sources and Test}

From the previous analysis and previous researches, we can know that there are several factors affecting the local officials' promotion about the issue of China's local officials' promotion incentive, including economic performances, political relationships, and financial performances.

Because of the few samples of Chinese province officials, the outcome may have statistical errors. On the other hand, selecting the Chinese country officials is hard, which can cause the difficulty of collecting data. In the end, Chinese city officials are the best samples to analyze the factors of official promotion incentive. We collect the panel data of city officials from 2001 to 2010 and the sample size is about 1,000. Above data sources respectively are: related data on Prefectural Party Secretary of P. R. China during the period of 2001-2010; data collected through the central government's websites, such as "Xinhua”, "People’s Daily”, and related data collected by hand from other official websites.

In the meantime, in order to analyze whether economic performances, political relationships, and financial performances can impact on official promotion, we also gather other variables, such as $C g$ (officials in the prefecture level city GDP of average tenure); $D \_g$ (officials in the prefecture level city growth and the provincial economic growth difference of average tenure); rate $g$ (urban GDP growth rate province GDP growth rate proportion within a term); ave_pg (per capita GDP growth rate), and brith_rate (the birth rate of the city), which all belong to economic performances variables. As for political relationships variables, we have: party_year (party standing); tuanwei (whether worked in Youth League Committee), and party_edu (whether graduated from Party School of the CPC). Finally, financial performances variables include: pro_ $g$ (the city tax growth rate); tax $g$ (industrial and commercial tax growth rate), and reve_g (fiscal revenue growth). Above variables are all gathered from Chinese City Statistical Yearbook and The New China 60 Years Statistical Data Collection.

From 2001 to 2010, the number of leader officials of 303 cities is about 3,664, including unqualified data and data of reappointment officials. And the official promotion rates had declined from 2001 to 2010 as shown in Figure 1.

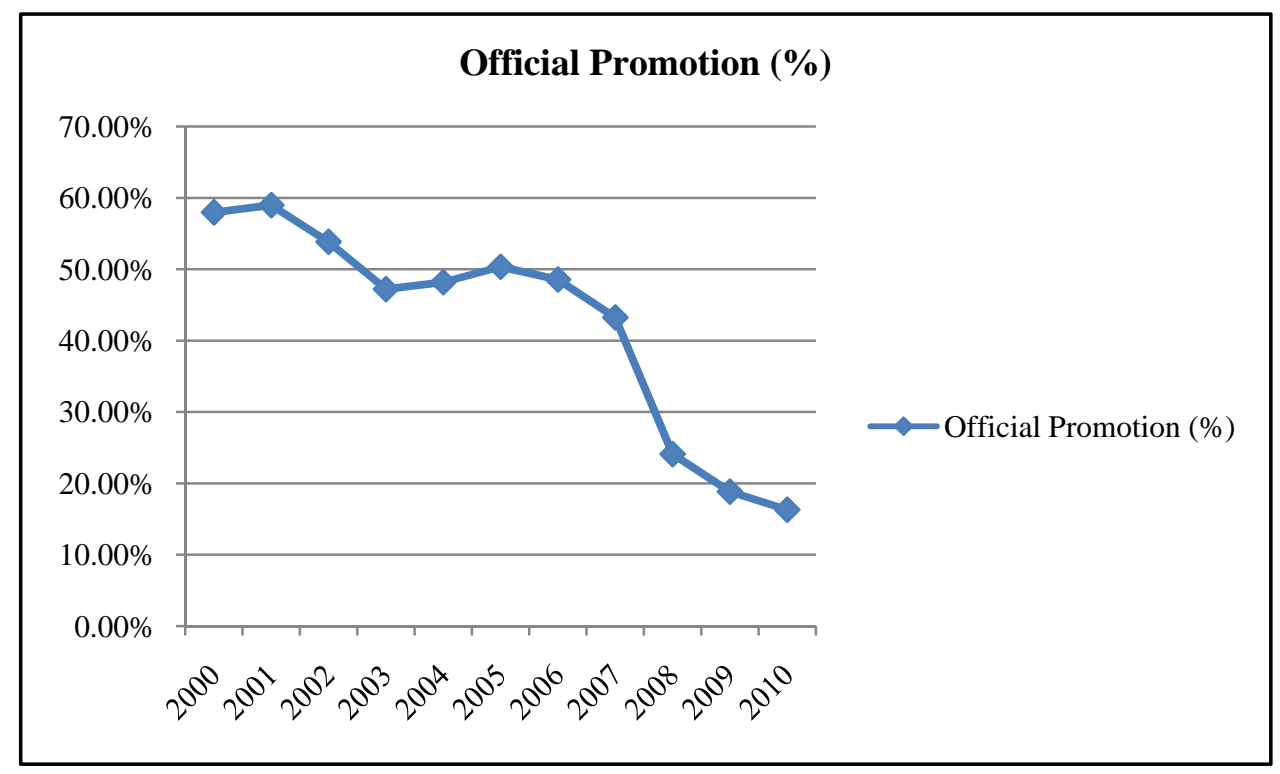

Figure 1. Official promotion rates (2001-2010). 
In order to find out the factors affecting the officials' promotion incentive, this paper selects the economic performances, political relationships, and financial performances for empirical study and analysis. Through the OLS models available:

$$
D=\alpha+\alpha 1 A+\alpha 2 B+\alpha 3 C+\varepsilon
$$

where $D$ is a dummy variable of official promotion; $A$ is related to economic performance variables; $B$ means control variables for political relations; and $C$ stands for fiscal revenue related variables.

We can get the result as follows: By analyzing the previous researches and papers, we can know that the economic performances have the biggest influence on local officials' promotion incentive. As a result, we select firstly economic performances variables by controlling other variables to find out their outcome which can be seen in Table 1.

Table 1

Official Promotion and Economic Performances

\begin{tabular}{|c|c|c|c|c|c|c|}
\hline Variable & (1) & $(2)$ & (3) & (4) & (5) & (6) \\
\hline valiavie & $\mathrm{FE}$ & $\mathrm{FE}$ & FE & $\mathrm{FE}$ & $\mathrm{FE}$ & $\mathrm{FE}$ \\
\hline $\mathrm{Cg}$ & $\begin{array}{l}-0.165^{\text {**** }} \\
(-5.53)\end{array}$ & & & & & $\begin{array}{l}-0.241^{* * * *} \\
(-6.08)\end{array}$ \\
\hline$D \_g$ & & $\begin{array}{l}0.200^{* * *} \\
(7.15)\end{array}$ & & & & $\begin{array}{l}0.340^{* * *} \\
(8.25)\end{array}$ \\
\hline rate $\_g$ & & & $\begin{array}{c}0.0372 \\
(1.24)\end{array}$ & & & $\begin{array}{l}0.0272 \\
(0.79)\end{array}$ \\
\hline ave_pg & & & & $\begin{array}{l}-0.0297^{* *} \\
(-2.08)\end{array}$ & & $\begin{array}{l}0.124^{* * *} \\
(5.27)\end{array}$ \\
\hline birth_rate & & & & & $\begin{array}{c}-0.0296 \\
(-0.91)\end{array}$ & $\begin{array}{l}-0.000696 \\
(-0.02)\end{array}$ \\
\hline$N$ & 1,053 & 1,053 & 1,053 & 951 & 1,051 & 949 \\
\hline Control variables & Yes & Yes & Yes & Yes & Yes & Yes \\
\hline
\end{tabular}

Notes. $t$-statistics are in parentheses; ${ }^{*}: p<0.1,{ }^{* * *}: p<0.05$, and ${ }^{* * * *}: p<0.01$.

From the above table, we can see that when we controlled other variables, the impact of economic performance-related variables on the promotion of officials is very significant. To be specific, $\mathrm{Cg}$ variable (officials in the prefecture level city GDP of average tenure) and $D \_g$ variable (officials in the prefecture level city growth and the provincial economic growth difference of average tenure) will significantly improve officials' promotion probability $\left(-0.165^{* * *}\right.$ and $\left.0.200^{* * *}\right)$. In the meantime, ave_pg variable (per capita GDP growth rate) will also improve officials' promotion probability significantly $\left(-0.0297^{* *}\right)$. Such as Model (6) indicates that if increasing per unit of $\mathrm{Cg}$ variable, its official promotion probability will be declined by $24.1 \%$; however, if the GDP's difference between the cities and provinces is much bigger, it will improve the probability of officials' promotion more significantly (34\%), which is consistent with Chinese officials' promotion mechanism. Moreover, if per capita GDP growth rate increases per unit, its official promotion probability will be increased by $12.4 \%$. By analyzing above mechanism, we can know that if we control other variables, we will find that economic performances can impact significantly on local officials' promotion, which is consistent with previous researches.

So, when we remove the economic performances variables, we will just find out the political relationships' influences on promotion, because in China's political system, political factors are important factors influencing officials' promotion, which is a vital standard for officials. Since the beginning of the Chinese reform and opening up, China's top legislators have more and more focused on officials' economic 
performances, but political factors also have not been eliminated. From the previous researches, we cannot find many papers which researched the influence of political relationships on promotion, so we will attempt to focus on it. We select "whether graduated from Party School of the CPC" as a dummy variable which can replace the relationships between local officials and central officials or top officials. If local officials have this experience, we can set it as equaling to 1 , and 0 if otherwise. Then, we also select local officials by whether they worked in Youth League Committee or not, if they have this experience, we can set it to be equal to 1, and 0 if otherwise. These dummy variables can represent fully Chinese Communist Party playing an important role in political system and officials' promotion mechanism. In the end, we also select the data of "party_year" (party standing). To be specific, the outcome is shown in Table 2.

Table 2

Official Promotion and Political Relationship

\begin{tabular}{llccc}
\hline \multirow{2}{*}{ Variable } & $(1)$ & $(2)$ & $(3)$ & $(4)$ \\
\cline { 2 - 5 } party_edu & FE & FE & FE & FE \\
party_year & $0.816^{* * *}$ & & & $0.509^{* *}$ \\
tuanwei & $(3.98)$ & & & $(2.32)$ \\
& & 0.014 & -0.009 \\
Control variables & & $(0.71)$ & $0.539^{* *}$ & $(-0.42)$ \\
$N$ & Yes & & $(2.13)$ & $0.590^{* *}$ \\
$l l$ & 1,043 & Yes & Yes & $(2.18)$ \\
\hline
\end{tabular}

Notes. $t$-statistics are in parentheses; ${ }^{*}: p<0.1,{ }^{* *}: p<0.05$, and ${ }^{* * *}: p<0.01$.

Based on previous outcome, we can know that political relationships can influence significantly local officials' promotion. Indeed, the dummy variable "whether graduated from Party School of the CPC" can impact on promotion at a 99\% level; "local officials whether worked in Youth League Committee" can also impact on promotion at a 95\% level. However, the officials' party standing cannot significantly impact on it. In Model (4), if officials once studied at Party School of the CPC, the probability of promotion will increase $50.9 \%$; moreover, if they once worked at Youth League Committee, the probability of promotion will increase $59 \%$.

If we eliminate the economic performances and political relationships factors, we can observe whether the financial performances factor has an impact on official promotion or not, which has been found to have a significant influence on official promotion by previous researchers. Because they think that since Chinese tax sharing reform in 1994, central government has been richer than local governments by gathering local finance to Beijing. So officials' promotion mechanism not only includes promoting local officials by economic performances, but central government needs also to observe the officials' skills for managing local finance. Thus, we also study the factor of financial performances. The outcome is shown in Table 3.

As Table 3 indicates, the financial performances of officials cannot impact on promotion significantly, although the city tax growth rate and fiscal revenue growth rate can have an impact at a $90 \%$ level. And the city's industrial and commercial tax growth rate cannot impact on it. We can see that fiscal revenue growth rate can increase $0.1 \%$ probability of promotion in Model (4). Overall, the financial performances of officials cannot impact on promotion significantly. 
Table 3

Official Promotion and Financial Performances

\begin{tabular}{llccc}
\hline Variable & $(1)$ & $(2)$ & $(3)$ & $(4)$ \\
\cline { 2 - 5 } & FE & FE & FE & FE \\
\hline pro_g & $-0.000^{*}$ & & & $-0.000^{*}$ \\
tax_g & $(-1.79)$ & -0.000 & & $(-1.79)$ \\
reve_g & & $(-0.03)$ & & 0.000 \\
Control variables & & & $0.001^{*}$ & $(0.05)$ \\
$N$ & Yes & Yes & $(1.96)$ & $0.001^{*}$ \\
ll & 1,041 & 1,041 & Yes & $(1.77)$ \\
\hline
\end{tabular}

Notes. $t$-statistics are in parentheses; ${ }^{*}: p<0.1,{ }^{* * *}: p<0.05$, and ${ }^{* * *}: p<0.01$.

To sum up, controlling the variables respectively, we can see that economic performances and political relationships can have a significant effect on officials' promotion except financial performances. To this issue, we will merge these variables and factors and observe and verify the synthesis outcome. The specific outcome is shown in Table 4.

Table 4

The Factors of Official Promotion

\begin{tabular}{|c|c|c|c|c|c|c|}
\hline \multirow{2}{*}{ Variable } & $(1)$ & $(2)$ & (3) & (4) & (5) & (6) \\
\hline & FE & $\mathrm{FE}$ & $\mathrm{FE}$ & $\mathrm{FE}$ & $\mathrm{FE}$ & FE \\
\hline \multirow[t]{2}{*}{ party_edu } & $0.364^{*}$ & $0.509^{* *}$ & $0.387^{*}$ & 0.309 & 0.354 & 0.269 \\
\hline & $(1.91)$ & $(2.32)$ & $(1.75)$ & (1.23) & (1.58) & (1.06) \\
\hline \multirow[t]{2}{*}{ party_year } & -0.020 & -0.009 & -0.012 & 0.021 & -0.017 & 0.017 \\
\hline & $(-1.20)$ & $(-0.42)$ & $(-0.64)$ & $(0.83)$ & $(-0.89)$ & $(0.64)$ \\
\hline \multirow[t]{2}{*}{ tuanwei } & 0.284 & $0.590^{* *}$ & 0.318 & 0.474 & 0.322 & 0.468 \\
\hline & (1.27) & $(2.18)$ & $(1.14)$ & $(1.45)$ & $(1.15)$ & $(1.42)$ \\
\hline \multirow[t]{2}{*}{$\mathrm{Cg}$} & & & $-0.256^{* * *}$ & $-0.262^{* * *}$ & $-0.265^{* * *}$ & $-0.274^{* * *}$ \\
\hline & & & $(-6.72)$ & $(-5.95)$ & $(-6.74)$ & $(-6.04)$ \\
\hline \multirow[t]{2}{*}{$D \_g$} & & & $0.390^{* * *}$ & $0.390^{* * *}$ & $0.396^{* * *}$ & $0.400^{* * *}$ \\
\hline & & & $(9.66)$ & $(8.43)$ & $(9.51)$ & $(8.47)$ \\
\hline \multirow[t]{2}{*}{ rate_g } & & & -0.002 & 0.041 & -0.006 & 0.037 \\
\hline & & & $(-0.07)$ & $(1.10)$ & $(-0.16)$ & $(0.98)$ \\
\hline \multirow[t]{2}{*}{ ave_pg } & & & $0.138^{* * *}$ & $0.135^{* * *}$ & $0.138^{* * *}$ & $0.136^{* * *}$ \\
\hline & & & $(5.95)$ & $(5.19)$ & $(5.78)$ & $(5.10)$ \\
\hline \multirow[t]{2}{*}{ brith_rate } & & & -0.030 & -0.003 & -0.022 & 0.005 \\
\hline & & & $(-0.73)$ & $(-0.07)$ & $(-0.52)$ & $(0.10)$ \\
\hline \multirow[t]{2}{*}{ pro_g } & & & & & -0.000 & -0.000 \\
\hline & & & & & $(-1.12)$ & $(-0.76)$ \\
\hline \multirow[t]{2}{*}{$\operatorname{tax} \_g$} & & & & & 0.001 & 0.001 \\
\hline & & & & & $(0.67)$ & $(0.65)$ \\
\hline \multirow[t]{2}{*}{ reve_g } & & & & & 0.001 & 0.001 \\
\hline & & & & & (1.45) & (1.52) \\
\hline Control variables & No & Yes & No & Yes & No & Yes \\
\hline$N$ & 1,111 & 943 & 996 & 847 & 988 & 839 \\
\hline ll & -507.633 & -399.753 & -375.394 & -300.396 & -367.027 & -293.437 \\
\hline
\end{tabular}

Notes. $t$-statistics are in parentheses; ${ }^{*}: p<0.1,{ }^{* * *}: p<0.05$, and ${ }^{* * * *}: p<0.01$. 
Through the analysis of the table, such as Model (2), it is shown that when we controlled the influential factors of financial income and economic performance on the official promotion, the influence of political relationship will also impact on official promotion. The central party school graduation experience will significantly improve official promotion probability $\left(0.509^{* *}\right)$; at the same time, if officials have experience in youth corps committee office, their promotion possibilities will also be improved $\left(0.590^{* *}\right)$. From Model (4), when "revenue" is under control, officials who will reduce the region's level of economic development will significantly increase the possibility of its promotion, when in the regional economic growth level relative to other cities in the province's leading level for every unit, its official promotion probability will be increased by $39.0 \%$, in line with the central "relative performance evaluation and selecting officials" intuitive experience and policy purposes; At the same time, if officials reduce the area of each unit growth in per capita GDP growth, the probability of official promotion will be increased by $13.5 \%$. Finally, when included in the "revenue" influence, both at the confidence levels of $99 \%$ to $40.0 \%$ and $40.0 \%$ respectively. That is to say, in order to get a promotion, officials will significantly increase the economic performance and construction of their own jurisdictions, and this project for political career will significantly increase the probability of its promotion.

\section{Conclusions}

By analyzing and testing the factors of influence of local officials' promotion incentive, we find that economic performances factor and political relationships factor can have a significant effect on officials' promotion, but financial performances factor cannot have this effect. Therefore, when officials based on their own political purposes and incentive region economic growth, the first choice is necessarily to promote regional investment growth. In the meantime, they should also focus on political relationships development.

\section{References}

Guo, G. (2007). Retrospective economic accountability under authoritarianism: Evidence from China. Political Research Quarterly, 60(3), 378-390.

Landry, P. F. (2003). The political management of mayors in post-Deng China. The Copenhagen Journal of Asian Studies, 17, 841-864.

Luo, D. L., She, G. M., \& Chen, J. (2015). A new re-examination of the relationship between economic performance and local leader' promotion: New theory and new evidence from city-level data. China Economic Quarterly, 3, 1145-1172. (in Chinese)

Qiao, K. Y., Zhou, L. A., \& Liu, C. (2014). Interim rank, promotion incentives and current performances: Evidence from the dynamic tournament among chinese local officials. China Journal of Economics, 3, 84-106. (in Chinese)

Tao, R., Su, F. B., Lu, L., \& Zhu, Y. M. (2010). Can economic development impact on promotion? Opposed to promotion tournament model and empirical test. Management World, 12, 13-26. (in Chinese)

Wang, X. B., \& Xu, X. X. (2008). The origin, disposition, tenure and economic development of local officials_—Based on Chinese provincial governors' evidence. Management World, 3, 16-26. (in Chinese)

Yang, Q. J., \& Zheng, N. (2013). Local officials promotion: Scaleplate tournament, promotion tournament and qualification tournament? The Journal of World Economy, 12, 130-156. (in Chinese)

Yang, R. L., Wang, Y., \& Nie, H. H. (2013). The promotion of “quasi-officials”: Based on central enterprises' evidence. Management World, 3, 23-33. (in Chinese)

Yao, Y., \& Zhang, M. Y. (2013). Performance of officials and the promotion tournament: Evidence from Chinese cities. Economic Research Journal, 1, 137-150. (in Chinese)

Zhou, L. A. (2007). Governing China’s local officials: An analysis of promotion tournament model. Economic Research Journal, 7, 36-50. (in Chinese) 